\title{
A paisagem e a vegetação na ilha de Curupu, litoral ocidental do estado do Maranhão
}

\begin{abstract}
A Ilha de Curupu constitui a principal unidade morfológica do Golfão Maranhense. Está localizada no nordeste da Ilha de São Luís e, regionalmente, figura como parte desta, pois durante a preamar os canais são inundados parecendo ambientes indissociáveis. Entretanto, politicamente, está integrada ao município de Raposa, próximo da capital maranhense, São Luís. A vegetação local é configurada pelas formações vegetais comumente encontradas na costa maranhense: os manguezais, as restingas, as dunas, as praias, os apicuns e marismas, além de formações vegetais secundárias resultantes do antropismo na ilha. Este estudo teve como objetivo principal levantar e caracterizar as principais unidades de paisagem e tipologias de vegetação da llha de Curupu, avaliando a sua ocorrência e distribuição na paisagem insular. Para tal, foi realizada a caracterização das principais unidades de paisagem e tipologias vegetacionais da llha de Curupu, sendo estas localizadas, classificadas e georreferenciadas. A amostragem da vegetação foi efetuada em 23 pontos, abrangendo todas as tipologias identificadas na Ilha, utilizando-se o método de parcelas. O levantamento fitossociológico resultou no registro e identificação 1.872 indivíduos pertencentes 52 espécies em 30 famílias. A vegetação exerce papel importante na paisagem geral da llha. As restingas exercem a proteção natural das dunas e dos campos mais baixos; os manguezais, proporcionam a proteção de igarapés que avançam do mar para o interior da llha. A matas de terra firme são responsáveis pela redução da exposição das áreas insulares à radiação solar direta, amenizando o clima na llha. São responsáveis também pela manutenção dos recursos hídricos na área, especialmente poços e pequenas lagoas temporárias. Na dimensão socioeconômica, embora a pesca seja a atividade principal na llha, a vegetação também ocupa seu espaço no provimento de variados produtos e serviços.
\end{abstract}

Palavras-chave: Ilha de Curupu; Maranhão; Vegetação; Fitossociologia; Conservação.

\section{The landscape and the vegetation in Curupu island, west coast Of the state of Maranhão}

\begin{abstract}
The Curupu Island is the main morphological unit of the Golfão Maranhense. It is located in the northeast of São Luís Island and regionally, appears as part of it, because during high tides making the flooded channels look like inseparable environments. However, politically, is integrated into the municipality of Raposa, near the capital of Maranhão, São Luís.The local vegetation is shaped by types commonly found in Maranhão coast: mangroves, salt marshes, dunes, beaches, apicuns and marshland, as well as secondary plant formations resulting from anthropism on the island. This study aimed to raise and characterize the main landscape units and vegetation types of Curupu Island, assessing their occurrence and distribution on the island landscape. For this, the main landscape units and vegetation types of Curupu Island were located, classified and geo-referenced. The vegetation sampling was performed on 23 points, covering all types identified on the island, using the plot method. The phytosociological survey resulted in the recording and identification of 1,872 individuals belonging to 52 species in 30 families. Vegetation plays an important role in the overall landscape of the island. Restingas exercise the natural protection of the dunes and the lower fields; mangroves provide protection to the water channels advancing from the sea to the interior of the island. The upland forests are responsible for reducing the exposure of island areas to direct solar radiation, softening the climate on the island. They are also responsible for the maintenance of water resources in the area, especially wells and small temporary ponds. In socioeconomic dimension, although fishing is the main activity on the island, the vegetation also takes its place in providing various products and services.

Keywords: Curupu Island; Maranhão; Vegetation; Phytosociology; Conservation.
\end{abstract}

Topic: Conservação da Biodiversidade

Reviewed anonymously in the process of blind peer.

Claudio Urbano Bittencourt Pinheiro

Universidade Federal do Maranhão, Brasil

http://lattes.cnpq.br/7511708130949687

cpinheiro@elo.com.br

Draytiane da Silva Machado

Universidade Estadual do Maranhão, Brasil

http://lattes.cnpq.br/5071251642606263

draytiane@bol.com.br

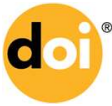

DOI: 10.6008/SPC2179-6858.2016.002.0007
Received: 10/01/2016

Approved: 15/04/2016
Referencing this:

PINHEIRO, C. U. B.; MACHADO. D. S.. A paisagem e a vegetação na ilha de Curupu, litoral ocidental do estado do Maranhão. Revista IberoAmericana de Ciências Ambientais, v.7, n.2, p.84-100, 2016. DOI: http://doi.org/10.6008/SPC2179-6858.2016.002.0007 


\section{INTRODUÇÃO}

A costa do Estado do Maranhão possui aproximadamente $640 \mathrm{~km}$ de extensão, sendo a 20 maior do Brasil. Estende-se da foz do rio Gurupi, na divisa com o Estado do Pará, até o Delta do rio Parnaíba, na divisa com o Estado do Piauí. Sua morfologia expressa uma faixa litorânea com três segmentos distintos: Costa Ocidental, Costa Oriental e Golfão Maranhense (FEITOSA, 1996).

O Golfão Maranhense está localizado no extremo norte do Estado do Maranhão e é constituído pelas baías de São Marcos e São José, que se encontram separadas pela llha de São Luís (AB'SABER, 1960. Esta região faz parte de uma zona costeira marcada por estuários e reentrâncias no noroeste do Maranhão, que “apresenta cerca de $5.414 \mathrm{~km}^{2}$ de manguezais, e no nordeste do Pará, com aproximadamente $2.177 \mathrm{~km}^{2}$ de manguezais" (SOUZA FILHO, 2005).

A llha de Curupu constitui a principal unidade morfológica do Golfão Maranhense. Está localizada no nordeste da llha de São Luís e, regionalmente, figura como parte desta, pois durante a preamar os canais são inundados parecendo ambientes indissociáveis (FEITOSA, 1996). Entretanto, politicamente, está integrada ao município de Raposa, próximo da capital maranhense, São Luís. A sua formação territorial se deu através da imigração de cearenses na região, que ao se estabelecerem constituíram a pesca como atividade principal e promoveram a ocupação da região, que por muito tempo fora isolada por não haver estradas que ligassem o município da Raposa à llha do Maranhão (RANGEL, 2003). A pesca e a atividade turística são atualmente as atividades de maior importância na ilha. Contudo, a vegetação existente na ilha também tem papel relevante na vida local, como fonte de alimentos e matérias primas variadas para construção e outras utilizações.

Os ecossistemas litorâneos são caracterizados por alta complexidade, sendo considerados áreas frágeis, por estarem sujeitos à interação de condicionantes climáticas, oceanográficas e continentais, além das modificações naturais, às modificações antrópicas (SANTOS, 2010). As condições naturais, a dinâmica e as modificações nos sistemas têm efeito direto sobre a vegetação e as populações com ela relacionadas. Para o ambiente, a vegetação tem papel crucial, por prover a proteção para os corpos d'água, para o controle do movimento de areia e formação das dunas. Para as populações locais, além dos serviços ambientais, são fontes de recursos, representando alimento, abrigo e materiais.

Avaliar e entender o papel da vegetação em suas diversas formações é importante para a conservação do ambiente insular e para a população local. A vegetação local é configurada pelas formações vegetais comumente encontradas na costa maranhense: os manguezais, as restingas, as dunas, as praias, os apicuns e marismas, além de formações vegetais secundárias resultantes do antropismo na ilha. Este estudo teve como objetivo principal levantar e caracterizar as principais unidades de paisagem e tipologias de vegetação da Ilha de Curupu, avaliando a sua ocorrência e distribuição na paisagem insular. 


\section{METODOLOGIA}

\section{Área de Estudo}

A llha de Curupu $\left(02^{\circ} 24^{\prime} 09^{\prime \prime}-02^{\circ} 27^{\prime} 1^{\prime \prime} \mathrm{S} ; 44^{\circ} 01^{\prime} 19^{\prime \prime}-44^{\circ} 06^{\prime} 52^{\prime \prime} \mathrm{W}\right)$ localiza-se no extremo nordeste da Ilha de São Luís, da qual é separada por um conjunto de canais do mar, constituindo a principal unidade morfológica do Golfão Maranhense. Está localizada a cerca de $30 \mathrm{~km}$ do centro da cidade de São Luís, capital do estado (Figura 1). Engloba uma faixa de terras delimitada ao Norte pelo Oceano Atlântico, ao Sul pelo Canal da Raposa, a Leste pela Baía de São José e a Oeste pela Baía de São Marcos (MARANHÃO, 2002). Com aproximadamente $14 \mathrm{~km}$ de praias, dunas e mangues, em $16 \mathrm{~km}^{2}$ de área, destaca-se em seu potencial turístico. Embora seja uma propriedade privada, seu território pertence ao município de Raposa, que na década de 1990 tomou-se independente do município de Paço do Lumiar (FREIRE et al., 1994).

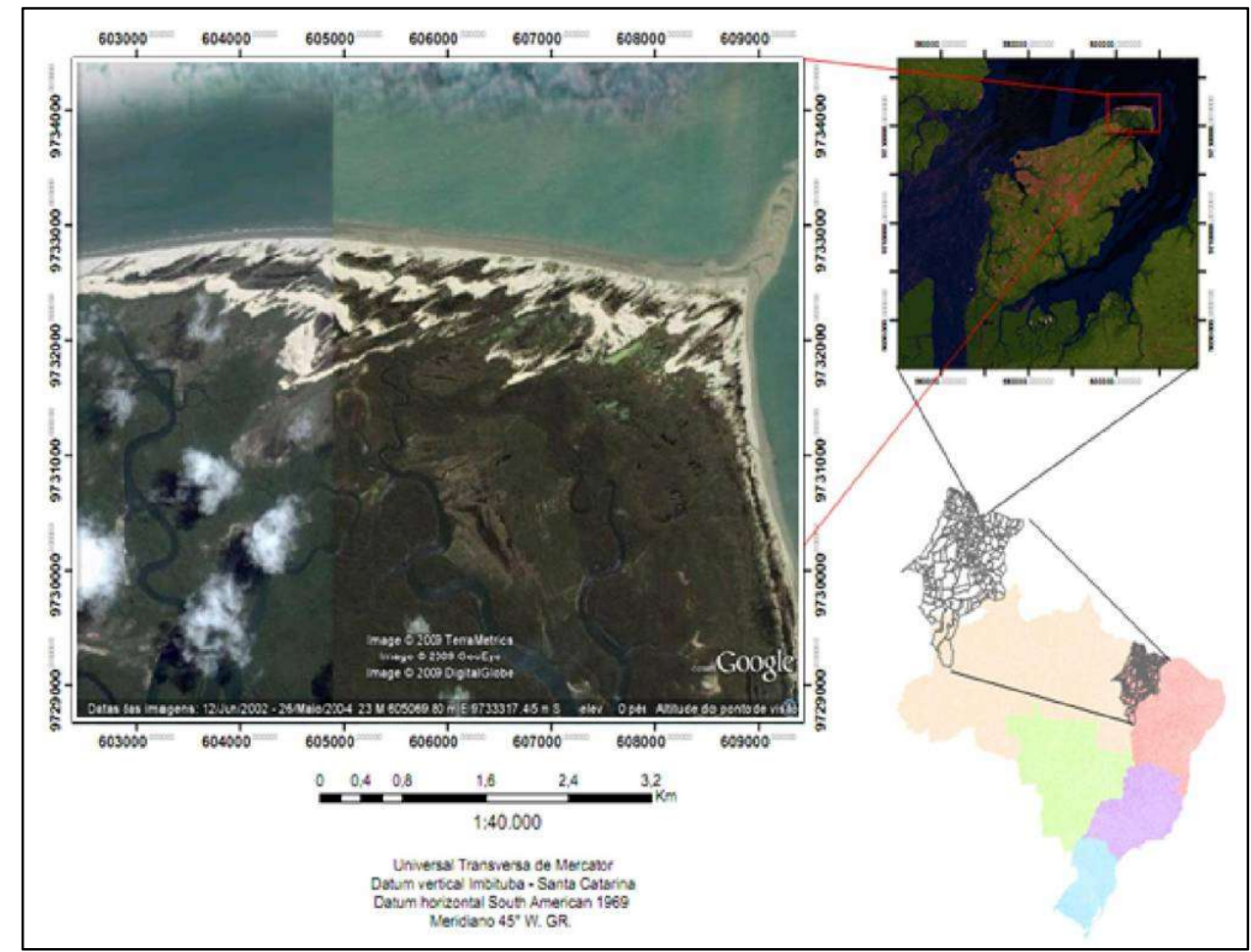

Figura 1: Localização da área de estudo. Fonte: Google (2012).

\section{Caracterização de Unidades de Paisagem e Tipologias Vegetacionais da Ilha de Curupu}

Com o trabalho de campo, além de imagens e fotografia aéreas, foram localizadas e classificadas as principais unidades de paisagem e tipologias vegetacionais da ilha. Na amostragem botânica nas tipologias de vegetação procurou-se caracterizar a composição de espécies vegetais, registrando-se as espécies presentes, o número de indivíduos por espécie, estágios sucessionais dos indivíduos e estado de conservação das espécies e áreas amostradas nas diferentes unidades de paisagem e tipologias de vegetação.

Para amostragem botânica foi utilizado o método de parcelas (BRAUN-BLANQUET, 1979; SCHAEFFERNOVELLI et al., 1986). Parcelas individuais de amostragem foram locadas na área de estudo em dimensões de 20 metros de comprimento por 10 metros de largura (200m2). Cada parcela foi identificada com plaqueta de plástico, contendo data, local e tipologia de vegetação amostrada, sendo fotografada. 
Foram locadas 23 (vinte e três) parcelas dentro da área de estudo, em um total de $4.600 \mathrm{~m} 2$ amostrados. Nas parcelas foram registradas todas as espécies vegetais ocorrentes, sendo os indivíduos contabilizados como jovens e adultos. Para cada indivíduo adulto contabilizado, registrou-se o hábito de crescimento, a circunferência a altura do peito (CAP; a 1,30m do solo) em indivíduos somente a partir de $10 \mathrm{~cm}$, além da altura aproximada, estágio de desenvolvimento e observações gerais sobre as plantas e o ambiente. Os indivíduos arbóreos com CAP abaixo de $10 \mathrm{~cm}$ foram classificados como jovens; aqueles com CAP acima de $10 \mathrm{~cm}$ foram considerados adultos. Esta noção técnica de fase de desenvolvimento (jovem e adulto) foi reforçada pelo exame visual dos indivíduos em relação à floração e/ou produção de frutos. Para os indivíduos jovens, foi efetuada apenas a contagem para avaliação da regeneração na área amostrada. A contagem de indivíduos com qualquer circunferência permitiu aferir o nível de regeneração dos indivíduos das espécies arbóreas, mostrando por esta via, os níveis atuais de regeneração.

A identificação das plantas foi efetuada inicialmente pelo nome comum local, por relato de informante-chave; posteriormente, foi procedida a identificação botânica das mesmas, utilizando-se espécimes botânicos, banco de dados já existente e imagens digitais das plantas no campo. Todos os locais de coleta foram georreferenciados. Os dados levantados nas parcelas amostradas foram submetidos a análises fitossociológicas, processados e analisados com o uso dos programas JMP (SAS, 2010) e Mata Nativa (CIENTEC, 2006).

\section{RESULTADOS E DISCUSSÃO}

As unidades de paisagem e tipologias de vegetação levantadas e classificadas na ilha de Curupu estão dispostas na Tabela 1.

Tabela 1. Unidades de Paisagem e Tipologias de Vegetação da Ilha de Curupu, Maranhão.

\begin{tabular}{|l|l|}
\hline Unidade de Paisagem & Tipologias Vegetacionais \\
\hline 1) Sistemas de Terra Firme & Mata Alta de Restinga (Secundária), Babaçuais \\
\hline $\begin{array}{l}\text { 2) Sistemas Flúvio-Marinhos } \\
\text { (Manguezais, Restingas, Apicuns, Marismas, Lagoas, Mata Baixa de Restinga, Campos de } \\
\text { Temporárias, Dunas e Praias) }\end{array}$ & $\begin{array}{l}\text { Mangue, Mestinga, Restinga de Cordões Arenosos (Dunas), Apicum, } \\
\text { Marisma, Macrófitas Aquáticas }\end{array}$ \\
\hline
\end{tabular}

\section{Terra Firme}

As áreas de Terra Firme ocupam as porções mais centrais da ilha, onde os solos, embora arenosos, apresentam menor salinidade, proporcionando desenvolvimento de vegetação arbórea e mais alta; nos limites dessas áreas, a penetração de igarapés possibilita a extensão de manguezais e apicuns.

Nesta unidade de paisagem, uma tipologia de vegetação se destaca na ilha, a Mata Alta de Restinga (chamada localmente de "Mata Alta") que, a rigor, constitui vegetação secundária. O processo de ocupação e uso da terra em Curupu deu origem ao aparecimento da vegetação secundária derivada da Mata Alta de Restinga que, em associação ou não, com a palmeira Attalea speciosa Mart. ex Spreng. (Babaçu), representa hoje, um tipo de vegetação relativamente comum na ilha (Figura 2).

Estas formações são caracterizadas por uma cobertura mais alta e mais densa, formando matas com árvores que ocupam as áreas de terra firme mais ao interior da ilha. São remanescentes de áreas originais de 
vegetação arbórea, com características de Restinga Arbórea original, embora na atualidade alteradas pelo uso continuado e efeitos gerais do antropismo. Nestas matas, o solo é arenoso, porém, apresenta maior teor de matéria orgânica, com menor salinidade que o solo das áreas litorâneas. A "Mata Alta" como é chamada localmente, está localizada posteriormente aos campos (Figura 2A).

Os babaçuais constituem formações vegetais monoespecíficas, sendo a palmeira Babaçu (Attalea speciosa Mart. ex Spreng.), a espécie principal. Os babaçuais substituem total ou parcialmente a floresta original, pela capacidade e agressividade do Babaçu como colonizador de áreas abertas pelo homem (PINHEIRO, 2012). Em Curupu, constituem hoje um tipo de vegetação comum na ilha, dominante em alguns pontos, ocorrendo em associação ou não com as capoeiras, pelo uso, ao longo do tempo, das áreas para atividades agrícolas (Figura 2B).

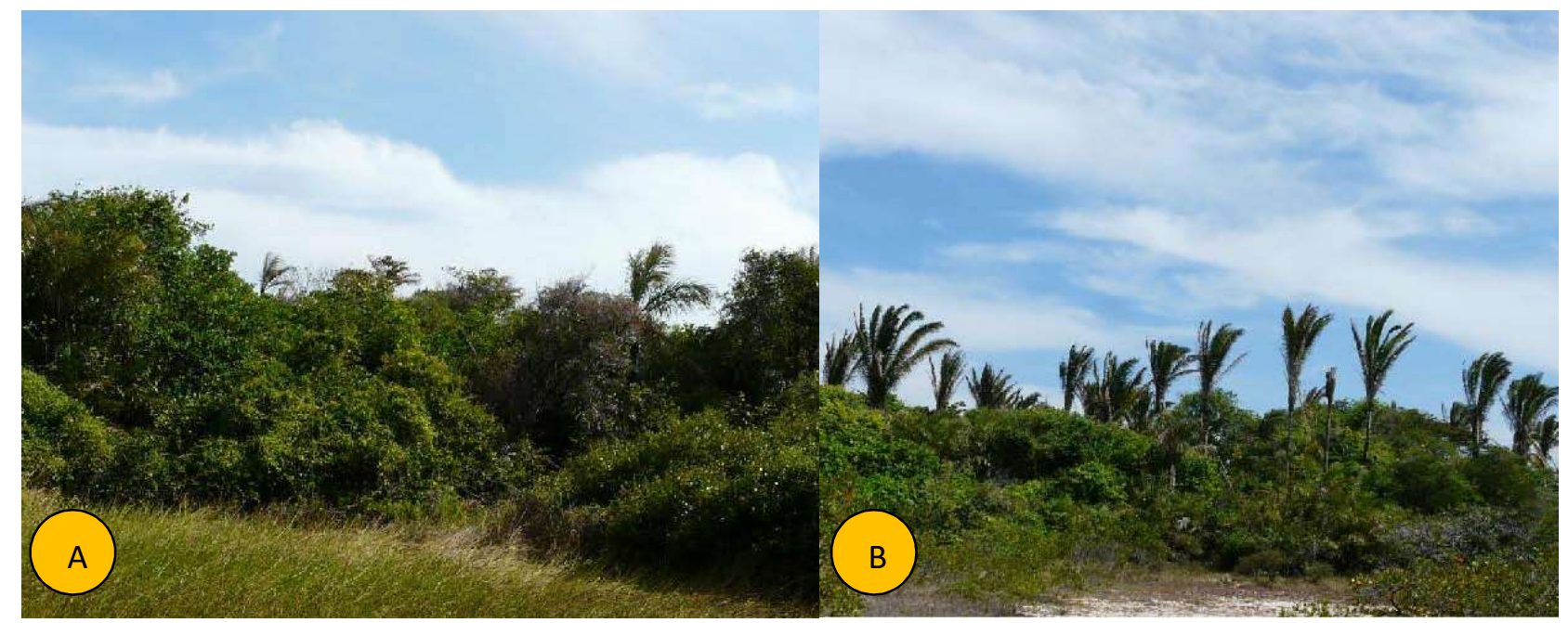

Figura 2: Vegetação em Terra Firme: A) Mata Alta de Restinga; B) Babaçu em associação com Mata Alta de Restinga. Fotos: Claudio Urbano B. Pinheiro.

\section{Sistemas Flúvio-Marinhos}

Incluem os Manguezais, os Apicuns, os Marismas Tropicais e as Restingas; estas últimas, diferenciadas em Matas Baixas de Restinga, Campos de Restinga e Restingas de Cordões Arenosos (Dunas). Adicionalmente, as Macrófitas Aquáticas, nas Lagoas Temporárias e a Vegetação Herbácea, nas Praias.

\section{Manguezais}

Vegetação arbóreo-arbustiva perenifólia densa, baixa, pobre em espécies, que ocorre nos estuários dos rios. Estende-se pelo litoral brasileiro desde Santa Catarina até o Amapá, seguindo rumo norte por toda a América tropical (REFLORA/JBRJ, 2016). Os manguezais são ambientes caracterizados pela influência direta das marés, comportando uma flora adaptada às variações de salinidade, Eh, pH e saturação em água. O manguezal apresenta espécies vegetais com aspecto bastante homogêneo, tanto do ponto de vista fisionômico quanto de sua composição florística, com restrito número de espécies forma populações muito densas. 
Ocupam as franjas dos igarapés em Curupu, constituindo uma importante formação vegetacional na ilha. Quatro espécies destes ambientes podem ser encontradas na ilha: Rhizophora mangle L., Rhizophoraceae (Mangue Vermelho) constitui a espécie mais frequente; seguindo-se Avicennia germinans (L.) L., Acanthaceae (Mangue Preto ou Siriba); Conocarpus erectus L., Combretaceae (Mangue de Botão); e Laguncularia racemosa Gaertn., Combretaceae (Mangue Branco). Os manguezais em Curupu não abrangem grandes áreas; contudo, constituem habitat para várias espécies de crustáceos e peixes, o que lhes confere elevado valor ecológico e socioeconômico (Figura 3).

\section{Apicuns e Marismas Tropicais}

Os apicuns são ambientes caracterizados pela elevada quantidade de sais, o que impede ou limita o desenvolvimento vegetal, diferenciando-se, desta forma, dos manguezais. São ecossistemas marinhos ecótonos, que agem como zonas de transição associadas aos manguezais. Ocorrem entre manguezais ou no interior dos mesmos, na interface médio/supralitoral. São ambientes definidos como áreas desprovidas de vegetação vascular, situada na região entre marés superior, inundada apenas pelas marés de lua nova e cheia (sizígias). Esta frequência quinzenal de inundação, associada com climas secos ou sazonalmente secos e a uma baixa declividade do terreno, é responsável pela hipersalinização do solo, erradicando a vegetação vascular. "As concentrações salinas geralmente superam 150 partes por mil” (SANTOS, 2005).

Em Curupu, os apicuns têm ocorrência localizada em vários pontos da ilha, onde as marés altas deixam sua marca hipersalina, formando estes ambientes com vegetação limitada à poucas espécies tolerantes à salinidade elevada. No seu entorno, contudo, os ambientes transicionais para terra firme, aparecem com formações vegetacionais variáveis de manguezais a formações de terra firme.

Os apicuns remanescentes em Curupu apresentam-se, na atualidade, bastante descaracterizados e de pequenas extensões. Aparentemente, as intervenções no entorno dos mesmos têm mudado a influência das marés, reduzindo a sua área e a sua condição de salinidade, permitindo o avanço de espécies mais oportunistas de terra firme e a sua consequente descaracterização (Figura 3).

\section{Marismas Tropicais}

Nas áreas entre marés, expostas a uma frequência de inundação, há altas salinidades. Nestas áreas classificadas como marismas tropicais (conhecidas popularmente como salgados), o mangue é ausente, com vegetação herbácea. Tecnicamente são classificados como marismas tropicais hipersalinos (SANTOS, 2005).

Segundo relatos locais, estas formações são resultado em grande parte do avanço e predominância da cunha salina, pela perda das lagoas de água doce, mais numerosas no passado. Estas formações halófilas aparecem esporadicamente onde o mangue não avançou ainda (Figura 3). Durante a estação chuvosa, muitas vezes uma pequena camada superficial é dessalinizada (alguns centímetros) e observa-se crescimento de vegetação herbácea. Contudo, mesmo na época de chuva, não acontece a dessalinização das camadas mais profundas, e assim está cobertura vegetal em crescimento é eliminada logo que terminada a estação chuvosa ou quando as raízes das plantas atingirem a camada hipersalina mais profunda (SANTOS, 2005). 


\section{Restingas}

Entende-se por vegetação de restinga (resolução CONAMA No. 07/1996), o conjunto de comunidades vegetais fisionomicamente distintas, sob influência marinha e flúvio-marinha, distribuída em mosaicos e que ocorrem em áreas com grande diversidade ecológica (SUGIYAMA, 1998). Assim como os manguezais, as restingas se estendem por quase toda a costa brasileira, numa extensão total de quase 5.000 quilômetros. A aparência desse ecossistema é muito variada, pois, na verdade, resulta de uma associação de ambientes diferentes. As restingas podem ser constituídas por matas, campos com predominância de gramíneas ou lagunas com vegetação aquática. Comparadas aos lamaçais costeiros dos manguezais, são ambientes novos e disputados pela vida animal e vegetal, inclusive o homem. "Por serem novos, são também instáveis e muito frágeis" (LACERDA, 1984).

Na região Nordeste do Brasil, a restinga compreende uma estreita faixa de vegetação ao longo de toda a costa, desde a foz do rio Parnaíba até o recôncavo Baiano e tem como principais características a presença de depósitos sedimentares de Formação Barreiras (Tabuleiros), as falésias e arenitos de praia, os recifes de coral e extensas áreas com dunas de grande porte (OLIVEIRA-FILHO et al., 1993). No Maranhão, Freire et al. (1994) estudaram a flora e a topografia das praias e dunas da llha de São Luís, registrando 260 espécies em 76 famílias, destacando-se a Fabaceae (24), Mimosaceae (12), Caesalpiniaceae (11), Myrtaceae (10), Poaceae (12) e Cyperaceae (8).

Segundo a resolução Conama no 004, de 18.09.1985, a restinga é uma acumulação arenosa litorânea, paralela à linha da costa, de forma geralmente alongada pelo mar, onde se encontram associações vegetais mistas características, comumente conhecidas como "vegetação de restinga". Os diferentes tipos de vegetação ocorrentes nas restingas brasileiras variam desde formações herbáceas, passando por formações arbustivas, abertas ou fechadas, chegando a florestas, cujo dossel varia em altura, geralmente não ultrapassando 20m (REFLORA/JBRJ, 2016). As formações herbáceas ocorrem principalmente na faixa de praia e ante dunas, em locais que eventualmente podem ser atingidos pelas marés mais altas, ou então em depressões alagáveis, situação na qual são comumente denominados de "brejos" ou "banhados" (ESKINAZILEÇA et al., 2004).

É um ecossistema costeiro, fisicamente determinado pelas condições edáficas (solos arenosos) e pela influência marinha, sendo que as espécies que ali vivem (flora e fauna) possuem mecanismos para suportar os fatores físicos dominantes como a salinidade, extremos de temperatura, forte presença de ventos, escassez de água, solo instável, insolação forte e direta, entre outros (ARAUJO et al., 1984). Os solos extremamente arenosos, não conseguem reter água e nutrientes em grande quantidade. Para sobreviver, as plantas desenvolveram mecanismos de obtenção de água com sistemas de raízes superficiais bastante extensos e de nutrientes, retirados da maresia presente na atmosfera. $\mathrm{O}$ ambiente das restingas abriga espécies com adaptações extremas, desde a vegetação hidrófila até a vegetação com caracteres xeromórficos, relacionados aos ambientes secos, em substratos arenosos que não retêm umidade (MENEZES et al., 2000). 
Em Curupu, ocorrem sobre planícies arenosas à beira mar apresentando vegetação arbórea, arbustiva e herbácea, em mosaico de ocorrência alternada, com fisionomia variada diretamente relacionada ao solo arenoso. Quatro fitofisionomias principais de restingas podem ser encontradas na ilha: As Matas Altas de Restinga (mais ao interior da ilha, já apontadas e descritas na unidade de Terra Firme), as Matas Baixas de Restingas, os Campos de Restingas e as Restingas de Cordões Arenosos.
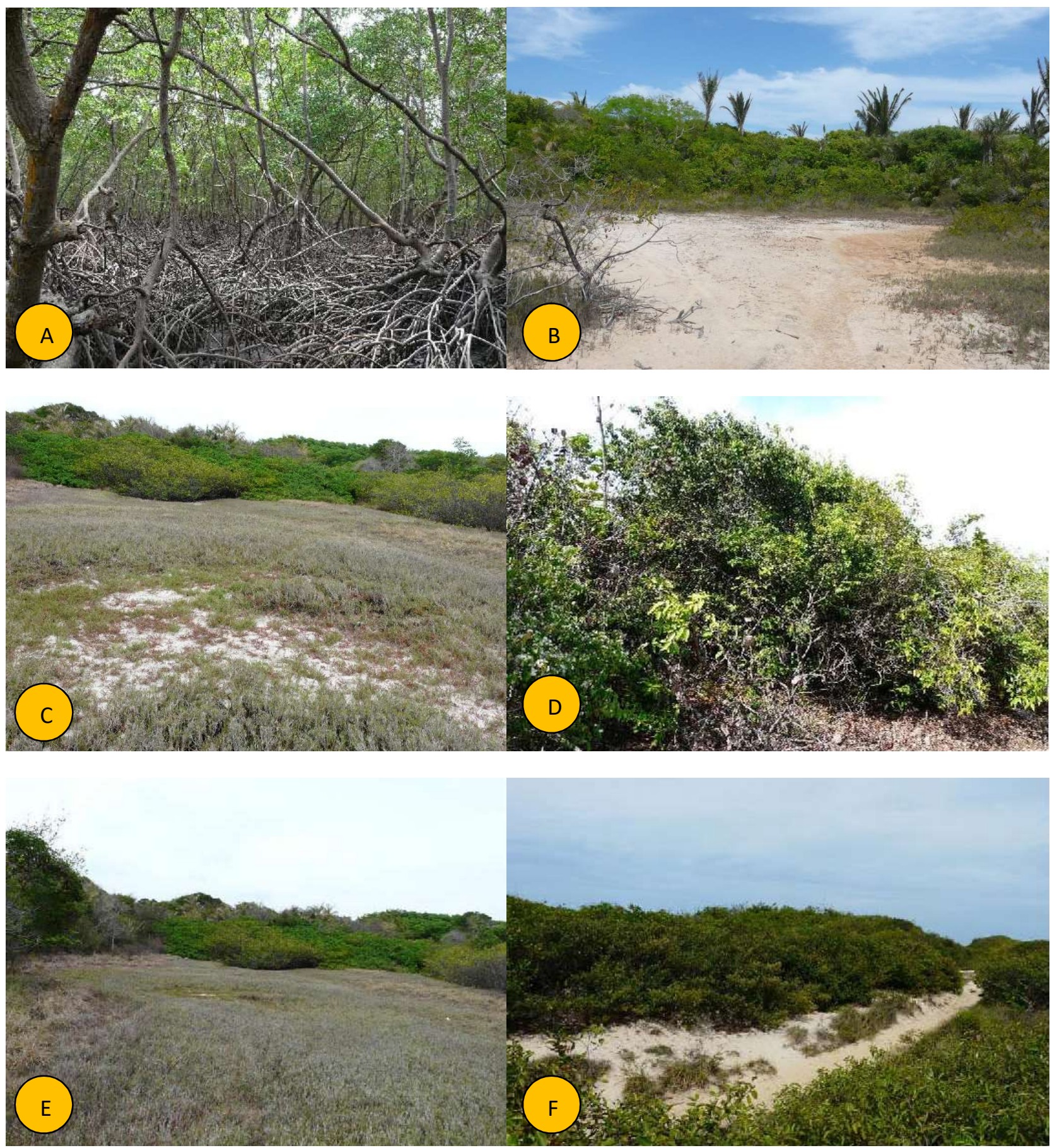

Figura 3: Sistemas Fluvio-Marinho em Curupu: A) Manguezal com Predominância de Rhizophora mangle L.; B) Apicum Descaracterizado em Borda de Manguezal; C) Marisma em Área Antropizada com Vegetação Herbácea; D) Mata Baixa de Restinga; E) Campo de Restinga; F) Restinga em Cordões Arenosos. Fotos: Claudio Urbano B. Pinheiro.

As Matas Baixas de Restingas localizam-se também mais para o interior da ilha, onde a vegetação é mais densa; nestas formações não há árvores altas, predominando as arvoretas, que não chegam, em média, 
a mais do que 5-6 metros de altura. Localizam-se com frequência nas bordas dos campos, em áreas mais baixas, mas não inundáveis (Figura 3).

Os Campos de Restingas estão localizados nas áreas mais baixas entre ou após os cordões arenosos. Caracterizam-se pela predominância de ervas e subarbustos, com indivíduos arbóreos e arbustivos esparsos; nas bordas formações arbóreas frequentes. São comuns espécies de ciperáceas, gramíneas e eriocauláceas na porção central desses ambientes (Figura 3).

As Restingas de Cordões Arenosos aparecem como formações onde as espécies são resistentes ao acúmulo de areia, constante exposição ao vento e altas temperaturas. Formam, em geral, um emaranhado capaz de reter a areia deslocada pelo vento, atuando, desta forma, na fixação destes cordões de pequenas dunas, com destaque, principalmente, para espécies de Byrsonyma (Murici), muito frequente, formando grandes adensamentos sobre as dunas (Figura 3), além de espécies reptantes, como (Ipomoea pes-caprae (L.) R. Br. (Salsa). Nestas áreas, as plantas não alcançam, em média, mais do que três metros de altura, por serem, em sua maioria, arbustos.

\section{Lagoas Temporárias}

Lagoas são corpos d'água rasos, de água doce, salobra ou salgada, em que a radiação solar pode alcançar o sedimento, possibilitando, consequentemente, o crescimento de macrófitas aquáticas. No Brasil, em geral, usa-se o termo lagoa para referir-se a todos os corpos d'água costeiros e mesmos interiores, independentemente de sua origem; no entanto, deve ser mencionado que esse procedimento não é correto, uma vez que muitas das lagoas costeiras são na realidade, lagunas (ESTEVES, 1998).

Formadas no período chuvoso, dão abrigo a um número de espécies de macrófitas aquáticas. No período de estiagem persistem as espécies com capacidade de enraizamento e resistência à seca (Figura 4). As plantas prosperam nas partes baixas inundadas pelo lençol freático durante a estação chuvosa e/ou pelas águas pluviais.
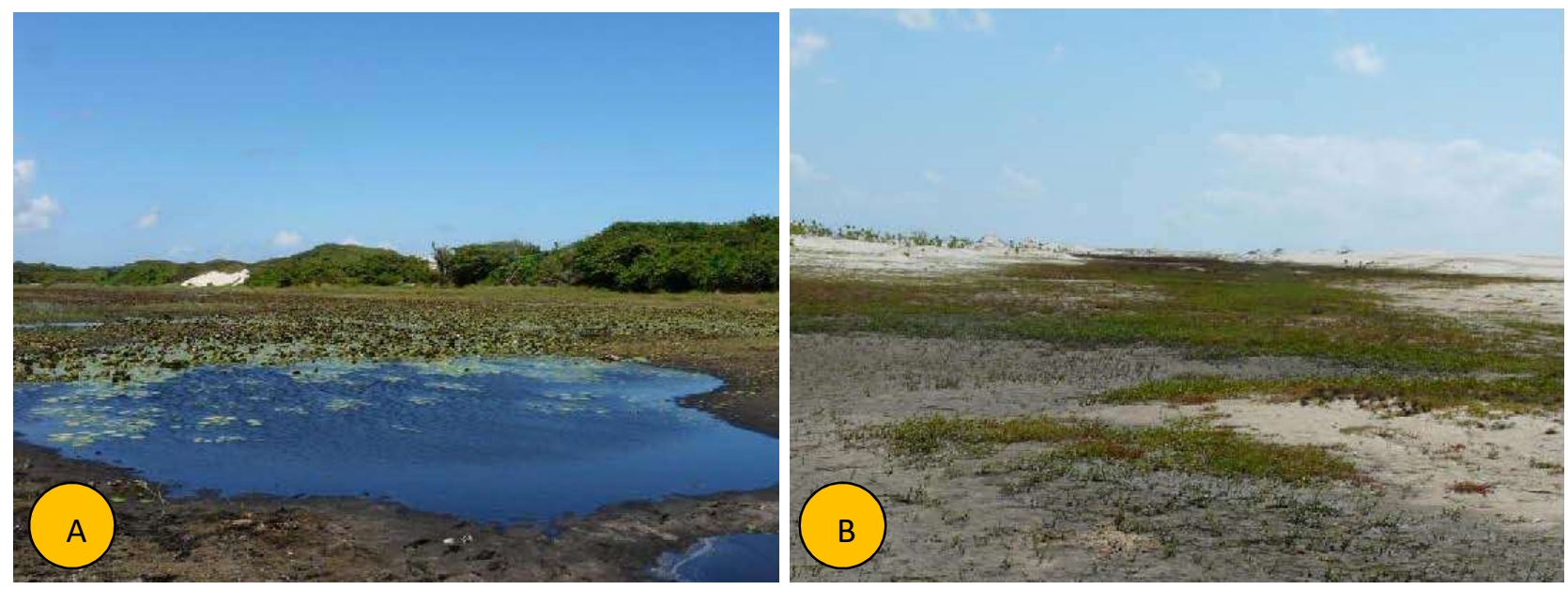

Figura 4: Lagoas Temporárias na Ilha de Curupu: A) Período Chuvoso, colonizadas por macrófitas aquáticas; B) Período de Estiagem - sem água e sem macrófitas. Fotos: Claudio Urbano B. Pinheiro.

\section{Praias}


Áreas sujeitas à influência de fatores ambientais, como marés, ventos, chuvas e ondas, o que faz com que seja uma região dinâmica. Parte da vegetação é considerada pioneira, colonizando espaços abertos em outras áreas, iniciando o processo de sucessão. É uma região de baixa diversidade de espécies. O substrato das praias é formado por areia de origem marinha e conchas. A granulometria e o tipo de mineral predominante variam ao longo da costa. O substrato é periodicamente inundado pela maré, o que limita o desenvolvimento de certos tipos de plantas e a ocorrência de certos grupos de animais.

\section{Fitossociologia das Tipologias de Vegetação da llha de Curupu}

No levantamento fitossociológico da llha de Curupu foram amostrados 1.872 indivíduos pertencentes de 52 espécies em 30 famílias, sendo 2 etnoespécies (não identificadas), nos 23 pontos amostrados. A Tabela 2 mostra o número de indivíduos por unidade de paisagem e tipologia de vegetação na área de estudo. A Tabela 9 apresenta a lista complete de espécies e a distribuição de ocorrência nas tipologias de vegetação.

Tabela 2: Número de Indivíduos Amostrados por Unidade de Paisagem na Ilha de Curupu, Maranhão.

\begin{tabular}{|l|c|}
\hline Unidade de Paisagem & Número de Indivíduos \\
\hline Terra Firme & \\
\hline . Mata Alta de Restinga (Secundária) & 1.292 \\
\hline & \\
\hline Sistemas Flúvio-Marinhos & 241 \\
\hline . Manguezal & 162 \\
\hline Restinga de Cordões Arenosos & 121 \\
\hline . Campo de Restinga & 40 \\
\hline . Mata Baixa de Restinga & 13 \\
\hline . Macrofitas Aquáticas (Lagoas) & 3 \\
\hline Apicum e Marisma & 580 \\
\hline Total (Sistemas Flúvio-Marinhos) & 1.872 \\
\hline Total Geral & \\
\hline
\end{tabular}

\section{Terra Firme: Mata Alta de Restinga}

Nesta unidade de paisagem foram amostrados 12 pontos, que totalizaram 1.292 indivíduos pertencentes a 33 espécies em 18 famílias; somente 1 indivíduo não foi identificado. Este conjunto vegetacional no interior da ilha de Curupu constituído pela Mata Alta de Restinga, na unidade de Terra Firme concentrou aproximadamente $70 \%$ do total de indivíduos amostrado e mais de $40 \%$ do total de espécies. Estas formações vegetais ocupam as partes mais altas e mais interiores da ilha.

As famílias mais frequentes foram: Myrtaceae pelo grande número de indivíduos de Myrcia selloi (Spreng) N. Silveira (Murta), Psidium kennedyanum Morong. (Araçá), outras espécies de Myrcia (Murta) e Campomanesia (Guabiroba); Burseraceae, pelo grande número de indivíduos de Protium heptaphyllum (Aubl.) March. (Breu Verdadeiro); Leguminosae, principalmente pela grande frequência de Copaifera sp. (Copaíba). A Tabela 3 mostra as nove espécies com maior número de indivíduos amostrados na Mata Alta de Restinga. Estas nove espécies foram responsáveis por mais de 82,5\% do total de indivíduos na terra firme; 
as demais 24 espécies registradas na Mata Alta de Restinga somaram apenas 17,5\% do total de indivíduos amostrados.

As Matas Altas de Restinga correspondem ao que a legislação de proteção das restingas (Resolução CONAMA No. 07/1996), denomina de Floresta Alta de Restinga, que prevê tal qual na área de estudo, vegetação com árvores que alcançam cerca de 10 a $15 \mathrm{~m}$ e com copas que se tocam. Embora em bom estado atual de regeneração, estes fragmentos denunciam a sua condição secundária por apresentarem um grande número de espécies já citadas nessa categoria, aparecendo Attalea speciosa Mart. ex Spreng. (Babaçu), Astrocaryum vulgare Mart. (Tucum), Myrcia spp. (Murta), Café Brabo (Unonopsis lindmanii Fries), Croaçu (Coccoloba latifolia Lam.), Celtis sp. (Papa Terra), entre outras. Contudo, espécies características destes ambientes, embora em pequeno número, aparecem também com um razoável número de indivíduos adultos, caracterizando a formação que em ambiente e composição assemelham-se às formações de restinga arbórea. Entre as espécies típicas destas formações, destacam-se a Copaíba (Copaifera sp.; Leguminosae), o Breu (Protium heptaphyllum (Aubl.) March.; Burseraceae), a Araçá (Psidium kennedyanum Morong.; Myrtaceae) e a Peroba (Jacaranda brasiliana (Lam.) Pers.; Bignoniaceae).

Árvore foi o hábito de crescimento de maior frequência nessa tipologia de vegetação $(86,92 \%)$, seguido de Palmeira (11,53\%), Erva (1,31\%) e Trepadeira $(0,23 \%)$. O estágio de desenvolvimento mais frequente entre os indivíduos amostrados nessa tipologia foi o de Jovens, com $44,72 \%$ do total; os adultos representaram 37,69\%; as plântulas, 17,57\%.

A altura (h) média encontrada em terra firme foi de $8,0 \mathrm{~m}$ e a circunferência a altura do peito (CAP) média de $22,0 \mathrm{~cm}$. Sendo árvores a maioria das espécies presentes nessas áreas, o padrão geral de altura e CAP revela um nível menor de perturbação nos últimos dez anos, conforme relatado por informantes da ilha, o que tem permitido uma certa regeneração da vegetação original das Matas Altas de Restinga.

Tabela 3: Número e Percentagem de Indivíduos das Principais Espécies na Mata Alta de Restinga, Ilha de Curupu, Maranhão.

\begin{tabular}{|l|l|c|c|}
\hline Espécie & Família & Número & Percentagem \\
\hline & & & 26,47 \\
\hline Protium heptaphyllum (Aubl.) March. & Burseraceae & 342 & 16,48 \\
\hline Myrcia selloi (Spreng) N. Silveira & Myrtaceae & 213 & 10,99 \\
\hline Copaifera sp. & Leguminosae & 142 & 8,12 \\
\hline Attalea speciosa Mart. ex Spreng. & Arecaceae & 105 & 5,57 \\
\hline Psidium kennedyanum Morong. & Myrtaceae & 72 & 4,02 \\
\hline Myrcia sp2. & Myrtaceae & 52 & 3,87 \\
\hline Astrocaryum vulgare Mart. & Arecaceae & 50 & 3,79 \\
\hline Alibertia edulis (L. Rich.) A. ex DC & Rubiaceae & 49 & 3,17 \\
\hline Campomanesia sp. & Myrtaceae & 41 & \\
\hline
\end{tabular}

\section{Sistemas Flúvio-Marinhos: Manguezal}

Nesse ambiente, foram levantados 241 indivíduos pertencentes a 4 espécies em 3 famílias. As famílias que mais se destacaram pelo número de indivíduos foram Rhizophoraceae pelo grande número de indivíduos de Rhizophora mangle L. (Mangue Vermelho), com 83,81\% e Acanthaceae, pelos indivíduos de Avicennia germinans (L.) L. (Siriba), com 13,28\% do total. (Tabela 4). 
Os indivíduos das espécies de mangue amostrados foram, em sua maioria jovens (53,11\%); os indivíduos adultos representaram 44,39\% do total; as plântulas foram apenas $2,49 \%$ do total de indivíduos amostrados. A altura (h) média dos indivíduos nos manguezais amostrados foi de 10,0m e a circunferência a altura do peito (CAP) média foi $18,0 \mathrm{~cm}$. Estas médias de altura em indivíduos de mangue em Curupu estão abaixo de valores registrados em áreas de manguezais em bom estado de conservação, os quais podem chegar a 30 metros de altura.

Os valores médios de altura e CAP em Curupu sugerem perturbações continuadas nesses ambientes. A ideia da perturbação nos mangues de Curupu é reforçada pelo elevado número de indivíduos jovens (superior a 50\%), evidenciando o estágio atual de regeneração, provavelmente pela extração frequente e continuada de madeira, como relatado por informantes locais. Os ecossistemas de manguezais da ilha de Curupu embora limitados em área física de abrangência são muito importantes no provimento de produtos e serviços ambientais aos habitantes da ilha.

Tabela 4: Número e Percentagem de Indivíduos Amostrados por Espécie na Vegetação de Mangue, Ilha de Curupu.

\begin{tabular}{|c|c|c|c|}
\hline Espécie & Família & Número & Percentagem \\
\hline Rhizophora mangle L. & Rhizophoraceae & 202 & 83,81 \\
\hline Avicennia germinans (L.) L. & Acanthaceae & 32 & 13,28 \\
\hline Conocarpus erectus L. & Combretaceae & 6 & 2,49 \\
\hline Laguncularia racemosa Gaertn & Combretaceae & 1 & 0,42 \\
\hline Total & & 241 & 100,00 \\
\hline
\end{tabular}

\section{Apicuns e Marismas}

Nas áreas amostradas de Apicuns foram registrados indivíduos de apenas três espécies em duas famílias: Marsileaceae (33,33\%), representada pelo Trevo Vermelho (Marsilea sp.); e Poaceae (66,66\%), representada pelo capim Paturá (Sporobolus virginicus Kunth.) e pelo Capim Açú (Paspalum ligurari Nee) (Tabela 5). A amostragem com poucas espécies reflete a época do ano. Embora aparentemente desprovidos de vida ativa, os apicuns tem sido objeto de polêmica no que se refere à sua utilização com áreas para a carcinicultura. Os que rejeitam esta possibilidade defendem a suposta condição sucessional dos apicuns associada aos manguezais. Os que defendem a utilização na carcinicultura não entendem como a possibilidade de se tornarem manguezais podem enquadrá-los como áreas protegidas, por uma condição futura com base em processo de sucessão que depende de muitos e incertos fatores de atuação (SANTOS, 2005).

Tabela 5: Número e Percentagem de Indivíduos Amostrados por Espécie em Apicum na Ilha de Curupu, Maranhão.

\begin{tabular}{|c|c|c|c|}
\hline Espécie & Família & Número & Percentagem \\
\hline Paspalum ligulari Nee & Poaceae & 1 & 33,33 \\
\hline Sporolobus virginicus Kunth. & Poaceae & 1 & 33,33 \\
\hline Marsilea sp. & Marsileaceae & 1 & 33,33 \\
\hline Total & & 3 & 100,00 \\
\hline
\end{tabular}


Nos Marismas, o hábito de crescimento é unicamente herbáceo. As espécies registradas nestes ambientes foram: Sesuvium portulacastrum L., Spartina alterniflora Lois, Blutaparon portulacoides e Paspalum vaginatum (St. Hill) Mears.

\section{Restingas: Mata Baixa de Restinga}

Neste tipo de Restinga foram amostrados 40 indivíduos pertencentes a 7 espécies em 7 famílias. A famílias com maior número de indivíduos foi a Rubiaceae pelo grande número de Alibertia edulis (L. Rich.) A. Rich ex DC (Jenipapinho) (Tabela 6). Os indivíduos amostrados apresentaram-se somente na forma de Árvores, com alto percentual de indivíduos jovens (67,50\%), e menor de adultos (32,50\%). A altura (h) média dos indivíduos amostrados na Mata Baixa de Restinga foi de 6,0m e a circunferência média a altura do peito (CAP) foi de $26,0 \mathrm{~cm}$.

Tabela 6: Número e Percentual de indivíduos Amostrados por Espécie na Mata Baixa de Restinga, Ilha de Curupu, Maranhão.

\begin{tabular}{|l|l|c|c|}
\hline Espécie & Família & Número & Percentagem \\
\hline & & & \\
\hline Alibertia edulis (L. Rich.) A. ex DC & Rubiaceae & 17 & 42,50 \\
\hline Myrcia selloi (Spreng) N. Silveira & Myrtaceae & 7 & 17,50 \\
\hline Byrsonima sp. & Malpighiaceae & 7 & 17,50 \\
\hline Coccoloba latifolia Lam. & Polygonaceae & 6 & 15,00 \\
\hline Anacardium occidentale L. & Anacardiaceae & 1 & 2,50 \\
\hline Guettarda angelica Mart. ex Mul. Arg. & Apocynaceae & 1 & 2,50 \\
\hline Mimosa artemisiana Heringer \& Paula & Leguminosae & 1 & 2,50 \\
\hline \multicolumn{2}{|r|}{ Total } & & $\mathbf{4 0}$ \\
\hline
\end{tabular}

\section{Restinga de Cordões Arenosos (Dunas)}

Na ilha de Curupu, estas formações ocorrem a partir da linha da praia, em dunas de baixa altura (23 metros, em média), predominando os arbustos, além de arvoretas esparsas. As famílias mais frequentes foram a Malpighiaceae e Anacardiaceae pelo grande número de indivíduos de Byrsonima sp. (Murici) e Anacardium occidentale L. (Caju), respectivamente (Tabela 7). O hábito de crescimento foi representado somente por arbustos nos cordões de areia da ilha, com predominância de adultos (93,82\% do total), com poucos jovens (apenas $6,17 \%$ ). A altura (h) média encontrada foi de $3,0 \mathrm{~m}$ e a circunferência a altura do peito (CAP) média de $21,0 \mathrm{~cm}$.

Tabela 7: Número e Porcentagem de Indivíduos Amostrados por Espécie em Restinga de Dunas, Ilha de Curupu - MA.

\begin{tabular}{|l|l|c|c|}
\hline Espécie & Família & Número & Percentagem \\
\hline & & & \\
\hline Byrsonima sp. & Malpighiaceae & 118 & 72,84 \\
\hline Anacardium occidentale L. & Anacardiaceae & 34 & 20,98 \\
\hline Guettarda angelica Mart. ex Mul. Arg. & Apocynaceae & 5 & 3,09 \\
\hline Allibertia edulis (L. Rich.) A. Rich. ex DC & Rubiaceae & 4 & 2,47 \\
\hline Sterculia chicha St. Hill. Ex Turpin & Sterculiaceae & 1 & 0,62 \\
\hline \multicolumn{1}{|r|}{ Total } & & $\mathbf{1 6 2}$ & $\mathbf{1 0 0 , 0 0}$ \\
\hline
\end{tabular}

\section{Campos de Restinga}


Áreas mais baixas entre ou após cordões arenosos, sujeitas a inundações sazonais, com predominância de estrato herbáceo de gramíneas e ciperáceas. São áreas condição predominantemente herbácea, destacando-se o Capim-açu (Sporolobus virginicus (L.) Kunth); em suas bordas, de áreas mais altas, menos sujeitas às inundações sazonais, as formações arbóreas das Matas Baixas de Restinga, já apresentadas. Pelo componente puramente herbáceo, dominado por poucas espécies, esta tipologia não recebeu amostragem formal.

\section{Macrófitas Aquáticas (Lagoas Temporárias)}

As lagoas da llha de Curupu são formadas no período das chuvas, possibilitando assim o aparecimento de macrófitas aquáticas; no período de estiagem, as lagoas secam, persistem apenas umas poucas espécies mais resistentes à seca sazonal.

Nas lagoas de Curupu, foram identificados 13 indivíduos pertencentes a 9 espécies de 4 famílias. As famílias encontradas foram a Poaceae, Cyperaceae, Azollaceae, Marsileaceae e Capparaceae. As espécies identificadas foram: Azolla sp. (Balsedo da Folha Miuda), Cleome spinosa L. (Mussambê), Eleocharis interstincta (Vahl) Roem \& Schult (Junco), Eleocharis sp. (Barba de Bode), Marsilea sp. (Trevo), Paratheria prostrata Griseb (Capim de Marreca), Paspalum repens Bergius (Capim Boiador), Cyperus ferax Rich. (Capim Botão) e Cyperus luzulae (L.) Rottb. ex Retz. (Tabela 8). O hábito de crescimento das espécies levantadas nas lagoas de Curupu foi somente Ervas.

A vegetação apresenta uma evidente sazonalidade anual de composição florística. No período de menor precipitação (julho a dezembro), poucas espécies sobrevivem. Em contrapartida, nos períodos de chuva (janeiro a junho), além destas espécies, surge uma flora mais diversificada.

Tabela 8: Número e Porcentagem de Indivíduos Amostrados por Espécie na Unidade de Paisagem Lagoa Temporária na Ilha de Curupu, Maranhão.

\begin{tabular}{|l|l|c|c|}
\hline Espécie & Família & Número & Percentagem \\
\hline & & & \\
\hline Azolla sp. & Azollaceae & 2 & 15,38 \\
\hline Marsilea sp. & Marsileaceae & 2 & 15,38 \\
\hline Eleocharis interstincta (Vahl) Roem. \& Schult. & Cyperaceae & 2 & 15,38 \\
\hline Paratheria prostrata Griseb. & Poaceae & 2 & 15,38 \\
\hline Cleome spinosa L. & Capparaceae & 1 & 7,69 \\
\hline Cyperus ferax Rich. & Cyperaceae & 1 & 7,69 \\
\hline Paspalum repens Bergius & Poaceae & 1 & 7,69 \\
\hline Cyperus luzulae (L.) Rottb. ex Retz & Cyperaceae & 1 & 7,69 \\
\hline Eleocharis sp. & Cyperaceae & 1 & 7,69 \\
\hline \multicolumn{1}{|c|}{ Total } & & $\mathbf{1 0 0 , 0 0}$ \\
\hline
\end{tabular}

Tabela 9: Lista Geral de Espécies, Famílias, Formas de Crescimento e Unidades de Paisagem de Ocorrência na Ilha de Curupu, Maranhão.

\begin{tabular}{|l|l|l|l|l|l|}
\hline No. & Nome Comum & Nome Botanico & Familia & Forma & U. Paisag. \\
\hline & & & & & \\
\hline 1. & Jenipapinho & Alibertia edulis (L. Rich.) A. Rich ex DC & Rubiaceae & Árvore & MA, MB, RD \\
\hline 2. & Caju & Anacardium occidentale L. & Anacardiaceae & Árvore & MA, MB, RD \\
\hline 3. & Angelim & Andira fraxinifolia Benth. & Leguminosae & Árvore & MA \\
\hline 4. & Tucum & Astrocaryum vulgare Mart. & Arecaceae & Palmeira & MA \\
\hline 5. & Mangue Preto & Avicennia germinans (L.) L. & Avicenniaceae & Árvore & M \\
\hline 6. & Balsedo da F. Miuda & Azolla sp. & Azollaceae & Erva & LT, C \\
\hline
\end{tabular}




\begin{tabular}{|c|c|c|c|c|c|}
\hline 7. & Murici & Byrsonima sp. & Malpighiaceae & Árvore & RD \\
\hline 8. & Guabiroba & Campomanesia sp. & Myrtaceae & Árvore & MA \\
\hline 9. & Papa Terra & Celtis sp. & Ulmaceae & Árvore & $\mathrm{MA}, \mathrm{MB}$ \\
\hline 10. & Mandacaru & Cereus sp. & Cactaceae & Árvore & $\mathrm{MA}, \mathrm{MB}, \mathrm{RD}$ \\
\hline 11. & Mussambê & Cleome spinosa $L$. & Capparaceae & Erva & $\mathrm{LT}, \mathrm{C}$ \\
\hline 12. & Croacu Folha Grossa & Coccoloba latifolia Lam. & Polygonaceae & Árvore & $\mathrm{MA}, \mathrm{MB}$ \\
\hline 13. & Carrasco & Connarus regnellii Schel. & Connaraceae & Árvore & $\mathrm{MA}, \mathrm{MB}$ \\
\hline 14. & Mangue Botão & Conocarpus erectus L. & Combretaceae & Árvore & $\mathrm{M}$ \\
\hline 15. & Copaíba & Copaifera sp. & Leguminosae & Árvore & MA \\
\hline 16. & Capim Botão & Cyperus ferax Rich. & Poaceae & Erva & $\mathrm{LT}, \mathrm{C}$ \\
\hline 17. & Amejú & Duguetia furfuracea (St. Hill) B. et H & Annonaceae & Árvore & MA \\
\hline 18. & Junco & Eleocharis interstincta (Vahl) Roem \& Schult. & Cyperaceae & Erva & $\mathrm{LT}, \mathrm{C}$ \\
\hline 19. & Barba de Bode & Eleocharis sp. & Cyperaceae & Erva & $\mathrm{LT}, \mathrm{C}$ \\
\hline 20. & Atracadeira & Ficus dendrocida Kunth. & Moraceae & Árvore & MA \\
\hline 21. & Angélica & Guettarda angelica Mart.ex Mul . Arg. & Rubiaceae & Árvore & $\mathrm{MA}, \mathrm{MB}, \mathrm{RD}$ \\
\hline 22. & Jatobá & Hymenaea courbaril L. & Leguminosae & Árvore & MA \\
\hline 23. & Ingá Ferrugem & Inga disticha Benth. & Leguminosae & Árvore & MA \\
\hline 24. & Ingá Rabo de Macaco & Inga edulis Mart. & Leguminosae & Árvore & MA \\
\hline 25. & Ingá & Inga sp. & Leguminosae & Árvore & MA \\
\hline 26. & Peroba & Jacaranda brasiliana (Lam.) Pers. & Bignoniaceae & Arvore & MA \\
\hline 27. & Mangue Branco & Laguncularia racemosa Gaertn & Combretaceae & Árvore & $\mathrm{M}$ \\
\hline 28. & Maniva de Viado & Manihot leptophylla Pax & Euphorbiaceae & Trepadeira & MA \\
\hline 29. & Maçaranduba & Manilkara huberi (Ducke) Cheval. & Sapotaceae & Árvore & MA \\
\hline 30. & Trevo & Marsilea sp1. & Marsileaceae & Erva & $\mathrm{LT}, \mathrm{AM}, \mathrm{C}$ \\
\hline 31. & Trevo Vermelho & Marsilea sp2. & Marsileaceae & Erva & LT, AM, C \\
\hline 32. & Jurema & Mimosa artemisiana Heringer \& Paula & Leguminosae & Árvore & $\mathrm{MA}, \mathrm{MB}$ \\
\hline 33. & Murta & Myrcia selloi (Spreng) N. Silveira & Myrtaceae & Árvore & $\mathrm{MA}, \mathrm{MB}$ \\
\hline 34. & Murta Verdadeira & Myrcia sp2. & Myrtaceae & Árvore & $\mathrm{MA}, \mathrm{MB}$ \\
\hline 35. & Murta Folha Miuda & Myrcia sp3. & Myrtaceae & Árvore & $\mathrm{MA}, \mathrm{MB}$ \\
\hline 36. & Babaçu & Attalea speciosa Mart. ex Spreng. & Arecaceae & Palmeira & MA \\
\hline 37. & Capim de Marreca & Paratheria prostrata Griseb & Poaceae & Erva & $\mathrm{LT}, \mathrm{C}$ \\
\hline 38. & Capim Açú & Paspalum ligurari Nee & Poaceae & Erva & $\mathrm{AM}, \mathrm{C}$ \\
\hline 39. & Capim Boiador & Paspalum repens Bergius & Poaceae & Erva & $\mathrm{LT}, \mathrm{C}$ \\
\hline 40 & Maracujá do Mato & Passiflora cincinnata Mast. & Passifloraceae & Trepadeira & $\mathrm{C}$ \\
\hline 41. & Cipó Traquá & Philodendron cordatum Kunth & Araceae & Trepadeira & MA \\
\hline 42. & Breu Verdadeiro & Protium heptaphyllum (Aubl.) March. & Burseraceae & Árvore & MA \\
\hline 43. & Araçá & Psidium kennedyanum Morong. & Myrtaceae & Árvore & MA \\
\hline 44. & Cascudo & Qualea sp. & Vochysiaceae & Árvore & $\mathrm{MA}, \mathrm{MB}$ \\
\hline 45. & Mangue Vermelho & Rhizophora mangle $L$. & Rhizophoraceae & Árvore & $\mathrm{M}$ \\
\hline 46. & Cipó de Japepanga & Smillax japecanga Griseb. & Smilacaceae & Árvore & $\mathrm{MA}, \mathrm{MB}$ \\
\hline 47. & Paturá & Sporobolus virginicus Kunth. & Poaceae & Erva & AM \\
\hline 48. & Axixá & Sterculia chicha St. Hill. ex Turpin & Sterculiaceae & Árvore & $\mathrm{MA}, \mathrm{MB}, \mathrm{RD}$ \\
\hline 49. & Pau d'arco roxo & Tabebuia sp. & Bignoniaceae & Árvore & MA \\
\hline 50. & Café Brabo & Unonopsis lindmanii Fries & Annonaceae & Árvore & $\mathrm{MA}, \mathrm{MB}$ \\
\hline 51. & Pau de Rêgo & $\mathrm{NI}$ & $\mathrm{NI}$ & Árvore & MA \\
\hline 52. & Cipó de Mulungú & $\mathrm{NI}$ & $\mathrm{NI}$ & Trepadeira & MA \\
\hline
\end{tabular}

$\mathrm{MA}=$ Mata Alta de Restinga; $\mathrm{M}=$ Manguezal; $\mathrm{C}=$ Campo de Restinga; LT= Lagoa Temporária; $\mathrm{AM}=\mathrm{Apicum} \mathrm{\&} \mathrm{Marisma;}$ $\mathrm{RD}=$ Restinga de Dunas; $\mathrm{MB}=$ Mata Baixa de Restinga; $\mathrm{NI}=$ Não Identificada.

\section{CONCLUSÕES}

O conjunto vegetacional da ilha de Curupu é formado principalmente por restingas, manguezais, campos, apicuns e marismas, nas áreas de influência direta do mar; matas altas de restinga secundárias e babaçuais, na terra firme, mais ao interior da ilha. Nas lagoas temporárias a ocorrência e abundância das espécies aquáticas estão condicionadas aos períodos de chuva e de estiagem. Nas praias, a vegetação é herbácea e limitada.

Na dimensão ambiental, a vegetação tem papel importante na ilha de Curupu, por prover a proteção para os corpos d'água, para o controle do movimento de areia, na formação e manutenção dos sistemas 
dunares. As restingas exercem a proteção natural das dunas e dos campos mais baixos; os manguezais, proporcionam proteção aos igarapés que avançam do mar para o interior da ilha. Na dimensão socioeconômica, embora a pesca seja a atividade principal na ilha, a vegetação também ocupa seu espaço no provimento de alimentos, principalmente frutos, fibras, madeira e lenha, além de produtos de subsistência de baixas quantidades, oriundos das diferentes formações vegetais.

As matas de terra firme são responsáveis pela redução da exposição das áreas insulares à radiação solar direta, amenizando o clima na ilha. São responsáveis também pela manutenção dos recursos hídricos na área, especialmente poços e pequenas lagoas temporárias. Desse modo, embora a pesca e a atividade de visitação turística sejam atividades de importância em Curupu, os recursos vegetais da ilha também papel relevante na vida dos locais, por contribuir indiretamente, mas decisivamente para a manutenção de fontes mínimas, mas consistentes de produtos de subsistência. Por outro, são diretamente responsáveis pela manutenção de serviços ambientais cruciais para a natureza da ilha e do seu povo.

Mesmo assim, várias áreas da ilha encontram-se bastante alteradas, devido a fatores como o turismo desordenado, o lixo de procedências diversas, desmatamentos, entre outros. Não existe plano de manejo ambiental da ilha. Medidas de conservação ambiental mais efetivas devem ser implementadas em Curupu para proteção dos recursos naturais; caso persista o nível atual de alteração, a tendência é a redução ou mesmo o desparecimento de espécies vegetais e animais.

O desenvolvimento sustentável não pode ser implementado sem o entendimento dos componentes dos ecossistemas e dos limites da sua sustentabilidade. Nesse sentido, a caracterização da vegetação e de suas espécies componentes, bem como em seu papel ambiental, socioeconômico e cultural, são de grande importância. As comunidades e espécies vegetais podem funcionar também como indicadores do potencial dos ecossistemas, mostrando o caminho para o planejamento da exploração segura e da conservação dos recursos naturais.

\section{REFERÊNCIAS}

AB'SABER, A. N.. Contribuição à geomorfologia do estado do Maranhão. Notícia Geomorfológica, v.3, n.5, p.35-45, 1960.

ARAUJO, D. S. D.; HENRIQUES, R. P. B.. Análise florística das restingas do estado do Rio de Janeiro. In: LACERDA, L. D.; ARAUJO, D. S. D.; CERQUEIRA, R.; TURCQ, B.. Restingas: origem, estrutura e processos. Niterói: CEUFF, 1984. p.159193

BRAUN-BLANQUET, J. B.. Fitosociología: base para el estudio de las comunidades vegetales. Madrid: H. Blume, 1979.

CIENTEC. Software Mata Nativa 2: sistema para análise fitossociológica, elaboração de inventários e planos de manejo de florestas nativas. Viçosa: CIENTEC, 2006.

ESKINAZI-LEÇA, E.; LEITÃO, S. N.; FERREIRA, M..

Oceanografia: um cenário tropical. Recife: Bagaço, 2004.

ESTEVES, F. A.. Fundamentos de Limnologia. 2 ed. Rio de Janeiro: Interciência, 1998.
FEITOSA, A. C.. Dinâmica dos processos geomorfológicos nas áreas costeiras do Nordeste do Maranhão. Tese (Doutorado em Geociências) - UNESP, Rio Claro, 1996.

FREIRE, M. C. C. M.; MONTEIRO, R.. Praias e dunas da llha de São Luís, estado do Maranhão (Brasil): florística e topografia. Arquivos de Biologia e Tecnologia, São Luís, v.37, n.4, 1994.

LACERDA, L. D.. Restingas: Origem, estrutura, processos. In: SIMPÓSIO SOBRE RESTINGAS BRASILEIRAS. Anais. Universidade Federal Fluminense, 1984.

MARANHÃO. Atlas do Maranhão. São Luís: GEPLAN, 2002.

MENEZES-SILVA, S.. Diagnóstico das restingas do Brasil. In: Workshop avaliação e ações prioritárias para a conservação da biodiversidade da zona costeira. Anais. Ilhéus, 2000.

OLIVEIRA- FILHO, A. T.; CARVALHO, D. A.. Florística e fisionomia da vegetação no extremo norte do litoral da 
Paraíba. Revista Brasileira de Botânica, São Paulo, v.16, n.1, 1993.

PINHEIRO, C. U. B.. Palmeiras do Maranhão: onde canta o sabiá. São Luís: Aquarela, 2011.

RANGEL, M. E. S.. Contribuição dos dados integrados dos sistemas sensores TM/LANDSAT-5 e ERS-1/SAR para 0 estudo de uso e cobertura da terra no nordeste da llha do Maranhão. Dissertação (Mestrado) - INPE, São José dos Campos, 2003.

REFLORA/JBRJ. Brazilian Flora 2020. Rio de Janeiro: Botanical Garden, 2016.

SANTOS, M. C. F. V.. Apicuns, salgados e manguezais e a ideologização do debate sobre a carcinicultura marinha brasileira. Revista da ABCC, n.4, 2005.

SANTOS, B. A. M. O.. Dinâmica da Paisagem da área leste do Município de São José de Ribamar, Estado do Maranhão. Monografia (Graduação em Geografia) - UFMA, 2010.

SAS. JMP Statistics and Graphis Guide, 10 vs. 2010.

SCHAEFFER-NOVELLI, Y.; CINTRÓN, G.. Guia para estudos de áreas de manguezal: estrutura, função e flora. São Paulo: Caribbean Ecological Research, 1986.

SUGIYAMA, M.. Estudo de florestas da restinga da Ilha do Cardoso, Cananéia, São Paulo, Brasil. Boletim do Instituto de Botânica, v.11, n.3, 1998.

SOUZA FILHO, P. W. M.. Costa de manguezais de macromaré da Amazônia: cenários morfológicos, mapeamento e quantificação de áreas usando dados de sensores remotos. Revista Brasileira de Geofísica, v.23, n.4, 2005. 